\title{
Towards a stable ion-solvating polymer electrolyte for advanced alkaline water
} electrolysis

Aili, David; Wright, Andrew G.; Kraglund, Mikkel Rykær; Jankova Atanasova, Katja ; Holdcroft, Steven; Jensen, Jens Oluf

Published in:

Journal of Materials Chemistry A

Link to article, DOI:

$10.1039 / \mathrm{c} 6 \mathrm{ta} 10680 \mathrm{c}$

Publication date:

2017

Document Version

Peer reviewed version

Link back to DTU Orbit

Citation (APA):

Aili, D., Wright, A. G., Kraglund, M. R., Jankova Atanasova, K., Holdcroft, S., \& Jensen, J. O. (2017). Towards a stable ion-solvating polymer electrolyte for advanced alkaline water electrolysis. Journal of Materials Chemistry A, 5(10), 5055-5066. https://doi.org/10.1039/c6ta10680c

\section{General rights}

Copyright and moral rights for the publications made accessible in the public portal are retained by the authors and/or other copyright owners and it is a condition of accessing publications that users recognise and abide by the legal requirements associated with these rights.

- Users may download and print one copy of any publication from the public portal for the purpose of private study or research.

- You may not further distribute the material or use it for any profit-making activity or commercial gain

- You may freely distribute the URL identifying the publication in the public portal 


\title{
Towards a stable ion-solvating polymer electrolyte for
}

\section{advanced alkaline water electrolysis}

\author{
David Aili, ${ }^{\mathrm{a},}{ }^{*}$ Andrew G. Wright, ${ }^{\mathrm{b}}$ Mikkel Rykær Kraglund, ${ }^{\mathrm{a}}$ Katja Jankova, ${ }^{\mathrm{a}}$ Steven Holdcroft ${ }^{\mathrm{b}}$ \\ and Jens Oluf Jensen ${ }^{\mathrm{a}}$ \\ ${ }^{a}$ Department of Energy Conversion and Storage, Technical University of Denmark, Kemitorvet 207, DK- \\ 2800 Kgs. Lyngby, Denmark, "Corresponding author (E-mail: larda@dtu.dk) \\ ${ }^{\mathrm{b}}$ Department of Chemistry, Simon Fraser University, Burnaby, British Columbia, Canada V5A 1S6
}

\begin{abstract}
Advanced alkaline water electrolysis using ion-solvating polymer membranes as electrolytes represent a new direction in the field of electrochemical hydrogen production. Polybenzimidazole membranes equilibrated in aqueous $\mathrm{KOH}$ combines the mechanical robustness and gas-tightness of a polymer with the conductive properties of an aqueous alkaline salt solution, and are thus of particular interest in this connection. This work presents a comprehensive study of ternary alkaline polymer electrolyte systems developed around a polybenzimidazole derivative that is structurally tailored towards improved stability in alkaline environment. The novel electrolytes are extensively characterized with respect to physicochemical and electrochemical properties and the chemical stability is assessed in $0-50 \mathrm{wt} \%$ aqueous $\mathrm{KOH}$ for more than 6 months at $88{ }^{\circ} \mathrm{C}$. In water electrolysis tests using porous 3-dimensional electrodes completely free from noble metals, it shows polarization characteristics comparable to that of commercially available separators and good performance stability over several days.
\end{abstract}


Keywords: polybenzimidazole, polymer electrolyte, stability, alkaline, water electrolysis

\section{Introduction}

Electrochemical water splitting through water electrolysis represents an attractive approach to store surplus electrical energy from renewable sources in form of hydrogen. ${ }^{1}$ Proton exchange membrane (PEM) systems based on perfluorosulfonic acid membranes operate at high current densities and produce hydrogen of high purity, but depend on noble metals such as platinum and iridium as catalysts. ${ }^{2}$ In alkaline environments, on the other hand, the oxygen ${ }^{3}$ and hydrogen ${ }^{4}$ evolution reactions readily occur on abundant materials, which is an important aspect when large scale implementation is considered. Alkaline water electrolyzers are durable and robust systems and have been commercially available for a long time, but the conventional systems suffer from high internal resistance. ${ }^{5}$ Reducing the interelectrode distance should thus be one of the key strategies in the development of cost-efficient and high-performing advanced alkaline water electrolyzers. ${ }^{6}$

One attractive approach in this connection is to replace the porous diaphragm with an anion conducting membrane. This allows for a cell design with gas-diffusion type electrodes in direct contact with the membrane and thus an interelectrode distance of less than $100 \mu \mathrm{m} .^{5}$ Anion exchange membranes based on quaternary ammonium functionalized polymers have received

much attention for this purpose recently, ${ }^{3,7}$ but improving the long term stability of the structural polymer backbone as well as of the anion exchange moieties in the hydroxide ionomer form remains a formidable challenge. ${ }^{8}$

An alternative concept is to construct the electrolyzer around an ion-solvating polymer electrolyte membrane system, combining the mechanical robustness and gas-tightness of a polymer with the conductive properties of an aqueous alkaline salt solution. ${ }^{9}$ Of special interest is 
the ternary polybenzimidazole $/ \mathrm{KOH} / \mathrm{H}_{2} \mathrm{O}$ electrolyte system, as first investigated systematically by Xing and Savadogo. ${ }^{10}$ It shows ion conductivity in a practically useful range and it has therefore been explored for technological use as electrolyte in hydrogen ${ }^{10-11}$ and direct alcohol ${ }^{12}$ fuel cells as well as in electrode binders ${ }^{13}$ and supercapacitors. ${ }^{14}$ The first implementation of this electrolyte system in alkaline water electrolysis was recently reported,${ }^{15}$ and by further optimization of the cell design it has been shown to outperform conventional state-of-the-art porous electrode separators even at significantly reduced $\mathrm{KOH}$ concentrations. ${ }^{16}$ The working principle is schematically depicted in Figure 1.

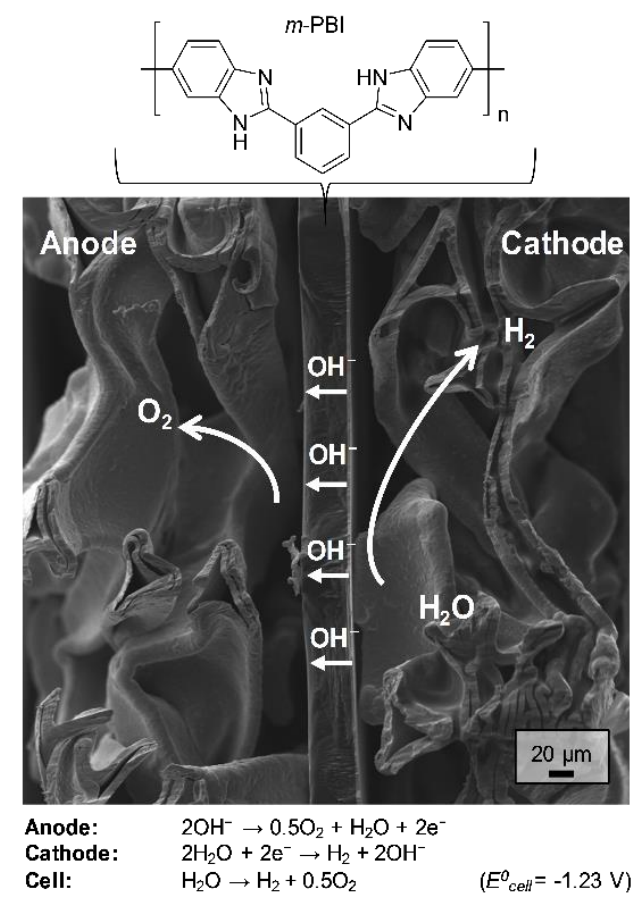

Figure 1 Working principle of an alkaline water electrolyzer based on polybenzimidazole as an ion-solvating polymer electrolyte membrane.

Of the different polybenzimidazole derivatives, poly(2,2'-( $m$-phenylene $)-5,5$-bibenzimidazole $)$ ( $m$-PBI, Figure 1) is traditionally the most widely used due to its good processing characteristics 
and straightforward synthesis from commercially available monomers. The membrane composition strongly depends on the $\mathrm{KOH}$ concentration of the bulk solution, which in turn determines virtually all physicochemical properties of the resulting membrane electrolytes. ${ }^{17}$ For example, the ion conductivity is increased by at least two orders of magnitude when the $\mathrm{KOH}$ concentration of the bulk solution is increased from 5 to $20-27$ wt $\%$ to reach well above $100 \mathrm{mS}$ $\mathrm{cm}^{-1} \cdot{ }^{10,17 \mathrm{~b}, 18}$ However, increasing the $\mathrm{KOH}$ concentration of the bulk solution significantly enhances the hydrolytic degradation of the structural base-polymer. ${ }^{18-19}$ Crosslinking effectively mitigates the deterioration of the mechanical integrity of the membrane, ${ }^{15 a}$ but does not increase the alkali resistance of the structural polymer backbone.

Towards the development of a stable alkaline ion-solvating polymer electrolyte a new polybenzimidazole derivative, poly(2,2'-(m-mesitylene)-5,5'-bibenzimidazole $)$ (mes-PBI), is used in the present work. Steric hindrance is used as design strategy to enhance the hydrolytic stability of the polymer backbone. ${ }^{7 f, 20}$ Ternary mes-PBI/KOH/ $\mathrm{H}_{2} \mathrm{O}$ electrolyte systems are prepared and extensively characterized with respect to composition, physicochemical properties and chemical stability in aqueous $\mathrm{KOH}$ with concentrations ranging from 0-50 wt\%. Furthermore, the membranes are tested as electrolytes in an advanced alkaline water electrolyzer using porous 3dimensional electrodes completely free from noble metals, showing polarization characteristics comparable to that of commercially available separators and good performance stability.

\section{Results and discussion}

\subsection{Membrane preparation and characterization}

Mes-PBI was prepared by a modified literature polymerization method, ${ }^{20 a}$ in which the polymerization of 2,4,6-trimethylisophthalic acid and 3,3'-diaminobenzidine in poly(phosphoric 
acid) was conducted under reduced pressure (Scheme 1) followed by a purification to remove small molecule impurities. Strong and flexible membranes of mes-PBI were obtained by dropcasting on glass dishes from DMSO.

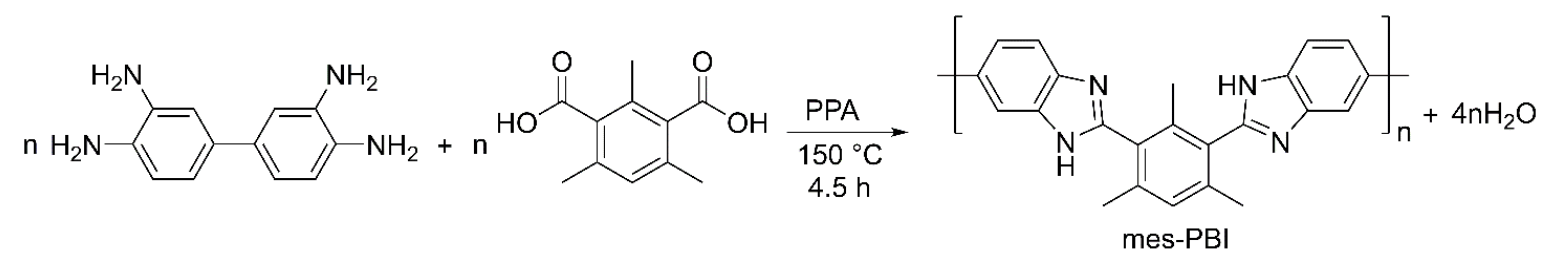

Scheme 1 Polycondensation of 3,3'-diaminobenzidine and 2,4,6-trimethylisophthalic acid to produce mes-PBI.

As shown in Scheme 2, a dynamic equilibrium between the pristine form of mes-PBI (left) and the deprotonated ionic form (right) is developed when submerged in aqueous $\mathrm{KOH}$. The position of the equilibrium depends on the concentration of the aqueous bulk $\mathrm{KOH}$ solution and shifts to the right when the concentration is increased, which also complicates the determination of the $\mathrm{KOH}$ content of the membrane matrix because part of the weight gain is due to the exchange of protons with potassium. ${ }^{17 \mathrm{~b}, 18}$

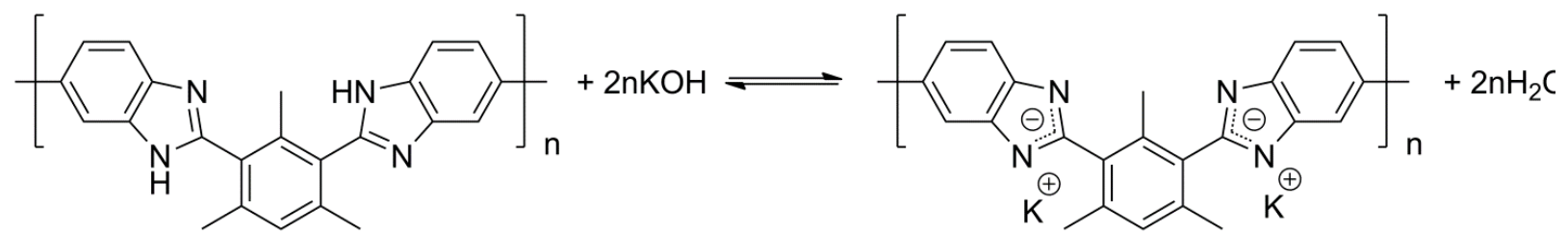

Scheme 2 Deprotonation of mes-PBI forming the corresponding potassium polybenzimidazolide repeat unit. 
The gravimetrically determined compositions of the mes-PBI membranes after equilibration in 0$50 \mathrm{wt} \%$ aqueous $\mathrm{KOH}$ are summarized in Figure 2a. The water uptake of the pristine mes-PBI membrane corresponded to about 3.4 molecules of water per polymer repeat unit, which is similar to that of $m$-PBI. ${ }^{21}$ The water uptake of mes-PBI increased with increasing $\mathrm{KOH}$ concentration and peaked in $25 \mathrm{wt} \% \mathrm{KOH}$, forming a ternary system composed of about $30 \mathrm{wt} \%$ water, $11 \mathrm{wt} \%$ $\mathrm{KOH}$ and $59 \mathrm{wt} \%$ mes-PBI. Taking the molar mass of the polymer repeat unit as $350 \mathrm{~g} \mathrm{~mol}^{-1}$, it corresponds to about 10.2 water molecules and $1.2 \mathrm{KOH}$ ion pairs per polymer repeat unit (Table 1). For comparison, the water uptake of $m$-PBI peaks when equilibrated in $15 \mathrm{wt} \% \mathrm{KOH}$, where it forms a mechanically robust polymer matrix with a polymer fraction of less than half of the total weight. ${ }^{17 \mathrm{~b}}$ As also observed for $m$-PBI, going towards higher $\mathrm{KOH}$ concentrations of the bulk solution resulted in increased $\mathrm{KOH}$ content and decreased water content within the mes-PBI matrix. Interestingly, the internal $\mathrm{KOH}$ concentrations of the mes-PBI membranes as calculated based on the weight of $\mathrm{KOH}$ relative to the combined mass of $\mathrm{KOH}$ and water were similar or slightly higher than the $\mathrm{KOH}$ concentration of the bulk solutions throughout the whole concentration range. 

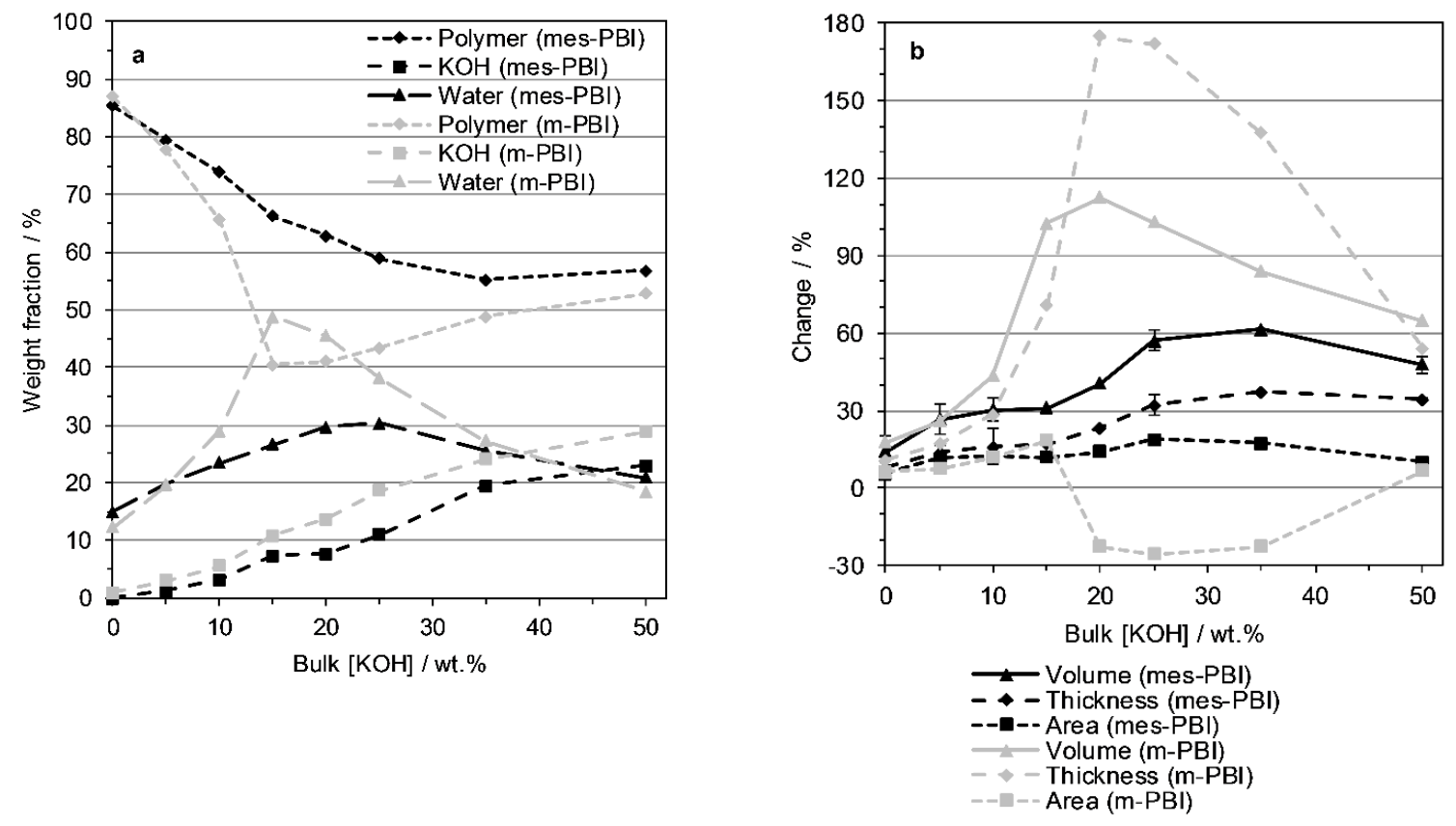

Figure 2 Composition with respect to the total weight (a) and dimensional changes relative to the dry mes-PBI membrane (b) of mes-PBI after equilibration in aqueous $\mathrm{KOH}$ with concentrations ranging from $0-50 \mathrm{wt} \%$ (black). The corresponding data for $m$-PBI are shown for comparison (gray). ${ }^{17 \mathrm{~b}}$

Table 1 Normalized water and $\mathrm{KOH}$ contents with respect to the polymer repeat unit (mes-PBI $\mathrm{RU}_{\text {) }}$ and corresponding water to $\mathrm{KOH}$ mole ratios.

\begin{tabular}{ll|llll}
\hline \multicolumn{2}{c|}{ Bulk solution } & \multicolumn{4}{|c}{ Polymer phase } \\
\hline$[\mathrm{KOH}](\mathrm{wt} \%)$ & $\mathrm{H}_{2} \mathrm{O} / \mathrm{KOH}$ & $\mathrm{H}_{2} \mathrm{O} / \mathrm{mes}_{-} \mathrm{PBI}_{\mathrm{RU}}{ }^{\mathrm{a}}$ & $\mathrm{KOH} / \mathrm{mes}_{-} \mathrm{PBI}_{\mathrm{RU}}{ }^{\mathrm{a}}$ & $\left.\mathrm{H}_{2} \mathrm{O} / \mathrm{KOH}\right)$ & {$[\mathrm{KOH}]$} \\
& & & & - & 0 \\
\hline 0 & - & 3.4 & - & 49.7 & 5.9 \\
10 & 60.2 & 4.8 & 0.1 & 23.7 & 11.6 \\
15 & 28.5 & 6.1 & 0.3 & 11.4 & 21.1
\end{tabular}




\begin{tabular}{ll|llll}
20 & 12.7 & 9.2 & 0.8 & 12.1 & 20.5 \\
25 & 9.5 & 10.2 & 1.2 & 8.6 & 26.5 \\
35 & 5.0 & 9.0 & 2.2 & 4.1 & 43.3 \\
50 & 3.2 & 7.1 & 2.5 & 2.8 & 52.3 \\
\hline
\end{tabular}

${ }^{\mathrm{a}}$ The molar mass of the polymer repeat unit was taken as $350 \mathrm{~g} \mathrm{~mol}^{-1}$.

In contrast to the anisotropic swelling behavior of $m$-PBI in aqueous $\mathrm{KOH}$ as repeatedly reported at concentrations higher than about $10 \mathrm{wt} \%,{ }^{12 \mathrm{~d}, 17}$ mes-PBI showed gradually increasing geometric surface area and thickness when the $\mathrm{KOH}$ concentration was increased from 0 to $35 \mathrm{wt} \%$ (Figure 2b). The volume swelling after equilibration in pure water and $35 \mathrm{wt} \%$ aqueous $\mathrm{KOH}$ was about 14 and $61 \%$, respectively. Further increasing the concentration of the bulk solution resulted in significantly reduced water content of the membranes and therefore decreased volume swelling, as also observed for perfluorosulfonic acid membranes in aqueous $\mathrm{KOH}^{22}$

Like for $m$-PBI, the FTIR spectrum of the water-equilibrated membrane based on mes-PBI shows several strong absorption bands in the $1240-1550 \mathrm{~cm}^{-1}$ region, assigned to different vibration modes of the benzimidazole groups (Figure 3a). ${ }^{23}$ The intensity of the absorption bands at 1540 and $1405 \mathrm{~cm}^{-1}$ was found to decrease with increasing $\mathrm{KOH}$ concentration and the bands were not visible after equilibration in aqueous $\mathrm{KOH}$ with concentrations higher than $20 \mathrm{wt} \%$. Instead, new absorption bands at $1600,1378,1345,1245$ and $1130 \mathrm{~cm}^{-1}$ were developed when the $\mathrm{KOH}$ concentration increased, as the acid-base equilibrium in Scheme 2 shifts towards the poly(2,2'-( $m$-mesitylene)-5, $5^{\prime}$-bibenzimidazolide) form of the polymer.

The ${ }^{1} \mathrm{H}$ NMR spectra of pristine mes-PBI (bottom) and of dried mes-PBI after equilibration in $50 \mathrm{wt} \% \mathrm{KOH}$ (top) are shown in Figure 3b. The peak assignments of pristine mes-PBI can be 
found elsewhere. ${ }^{20 a}$ After equilibration in aqueous $\mathrm{KOH}$, the ${ }^{1} \mathrm{H}$ NMR spectrum was poorly resolved due to low solubility in DMSO- $d_{6}$. However, the disappearance of the $-\mathrm{NH}$ signal at 12.7 ppm supports ionization of the polymer.

The XRD of mes-PBI that had been equilibrated in pure water showed a broad amorphous peak at $2 \theta=10-30^{\circ}$ (Figure 3c), likely composed of two convoluted peaks with peak maxima at $2 \theta$ about $16^{\circ}$ and $23^{\circ}$. As previously discussed by Kumbharkar et al. ${ }^{24}$ this is often seen for polybenzimidazole derivatives with bulky side chains due to the co-existence of different chain packing arrangements. For mes-PBI equilibrated in pure water the peak with a maximum at about $2 \theta=16.1^{\circ}$ correspond to a $d$-spacing of $5.50 \AA$ as calculated from the Bragg equation. Although the intensity of the amorphous peaks decreased significantly due to swelling when the concentration of the bulk solution reached $15 \mathrm{wt} \%,{ }^{17 \mathrm{~b}}$ the position of the peak at about $2 \theta=16^{\circ}$ did not change to a significant extent. The amorphous peak maximum at $2 \theta=23^{\circ}$, on the other hand, shifted towards higher angles when the $\mathrm{KOH}$ concentration of the bulk solution increased. At the same time the $d$-spacing decreased with increasing $\mathrm{KOH}$ concentration from 3.92 to $2.70 \AA$ in 0 and $50 \mathrm{wt} . \%$, respectively (Figure 3d). This is likely due to the increasing $\mathrm{KOH}$ content within the mes-PBI matrix, resulting in strengthened electrostatic interactions. This effect has also been observed for $m$-PBI in aqueous $\mathrm{KOH}$ at high concentrations and eventually resulted in crystallization of the polymer matrix. ${ }^{12 \mathrm{~d}, 17 \mathrm{~b}, 25}$ The $d$-spacing of mes-PBI equilibrated in water was significantly higher than that of $m$-PBI $(3.54 \AA),{ }^{17 b}$ likely due to the bulky structure giving a less efficient chain packing arrangements. ${ }^{24}$ 

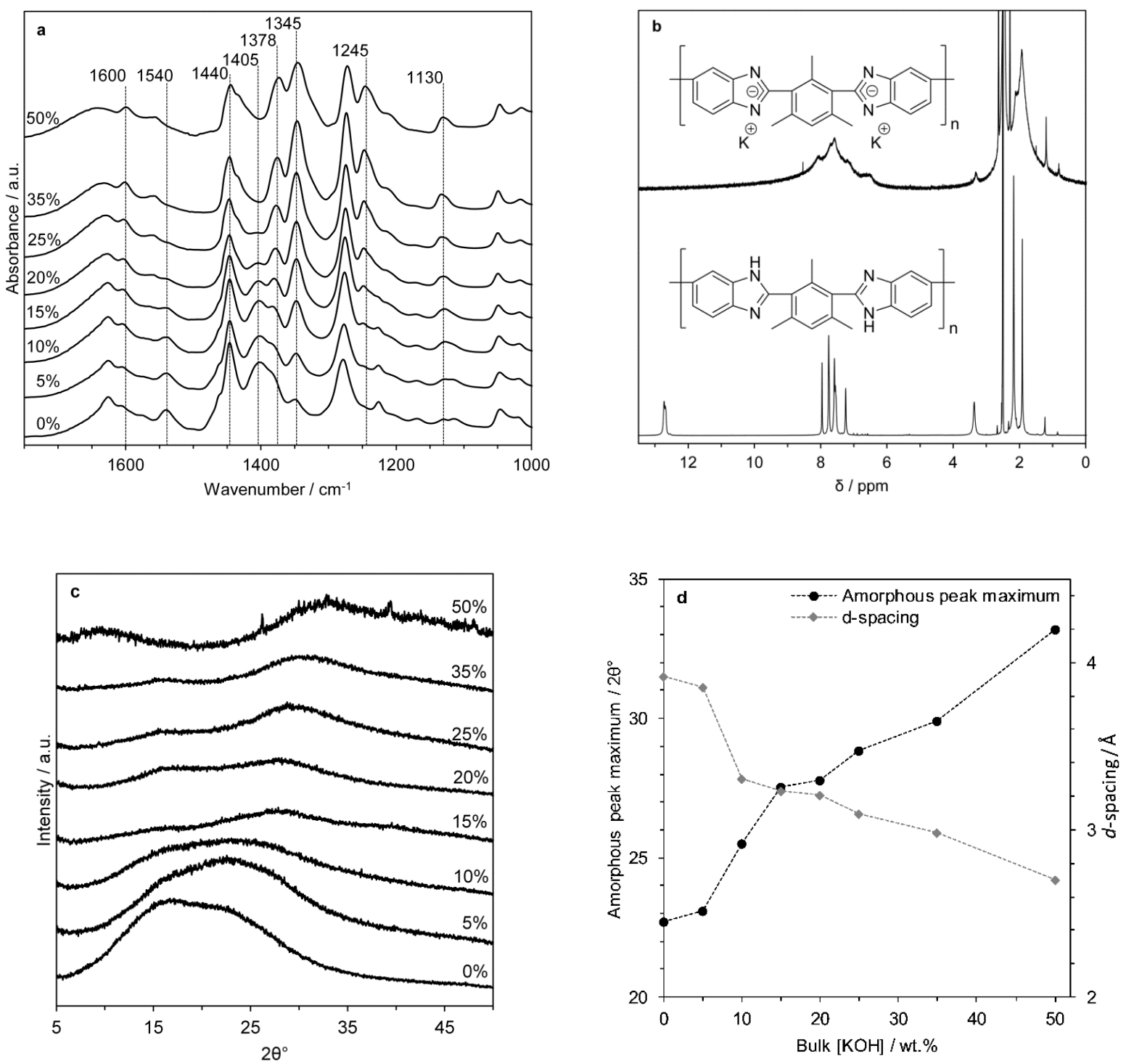

Figure 3 (a) FTIR spectra of mes-PBI equilibrated in aqueous $\mathrm{KOH}$ of concentrations ranging

from 0- $50 \mathrm{wt} \%$; (b) ${ }^{1} \mathrm{H}$ NMR spectra of mes-PBI in the pristine form (bottom) and in the potassium salt form (top); (c) XRD of mes-PBI equilibrated in aqueous $\mathrm{KOH}$ of concentrations ranging from 0- $50 \mathrm{wt} \%$ and (d) the corresponding amorphous peak maxima of the second peak and $d$-spacings.

\subsection{Electrochemical behavior}


The through plane ion conductivity of mes-PBI was recorded as a function of $\mathrm{KOH}$ concentration at $20-80{ }^{\circ} \mathrm{C}$, as shown in Figure $4 \mathrm{a}$. In $5 \mathrm{wt} \% \mathrm{KOH}$ the conductivity increased from 8 to $33 \mathrm{mS}$ $\mathrm{cm}^{-1}$ when the temperature was increased from 20 to $80{ }^{\circ} \mathrm{C}$. Enhanced conductivity in the low concentration regime is a major advantage, indicating that the electrolyzer can be operated at significantly reduced electrolyte concentrations than normally used. It would, in turn, result in a significant relief on the system and the auxiliary units, such as pumps, gas separators, and valves. By increasing the $\mathrm{KOH}$ concentration to $20 \mathrm{wt} \%$ the ion conductivity peaked at $25 \mathrm{mS} \mathrm{cm}^{-1}$ at 20 ${ }^{\circ} \mathrm{C}$, but decreased to $11 \mathrm{mS} \mathrm{cm} \mathrm{cm}^{-1}$ in $50 \mathrm{wt} \% \mathrm{KOH}$ due to the reduced water content of the membrane. The conductivity increased with increasing temperature and reached $88 \mathrm{mS} \mathrm{cm}^{-1}$ in 25 $\mathrm{wt} \% \mathrm{KOH}$ at $80{ }^{\circ} \mathrm{C}$.

The conductivity data were fitted to the Arrhenius equation (Equation 1 in logarithmic form), where $\sigma$ is the ion conductivity, $\sigma_{0}$ is the pre-exponential factor, $E_{a}$ is the activation energy, $T$ is the absolute temperature and $R$ is the universal gas constant.

$\ln (\sigma)=\ln \left(\sigma_{0}\right)-\left(E_{a} / R T\right)$

The Arrhenius plots are shown in Figure S1 and the corresponding activation energies are summarized in Table S1 (supporting information). The activation energies for ion conduction of the aqueous $\mathrm{KOH}$ solutions were found to be in the range $8-15 \mathrm{~kJ} \mathrm{~mol}^{-1}$ and tended to increase slightly with increasing $\mathrm{KOH}$ concentration, in good agreement with the predicted data. ${ }^{26}$ The activation energy of ion conductivity for the mes-PBI membrane was in the range $15-20 \mathrm{~kJ} \mathrm{~mol}^{-1}$ in 10-35 wt $\% \mathrm{KOH}$, which is slightly higher than for $m-\mathrm{PBI}^{16 \mathrm{~b}}$ and comparable to that of anion exchange membranes at intermediate to low water contents. ${ }^{27}$ 
a)

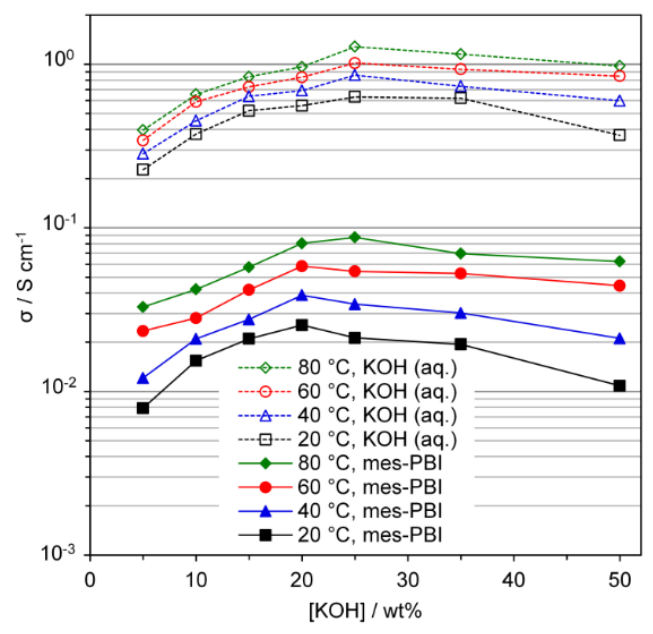

c)

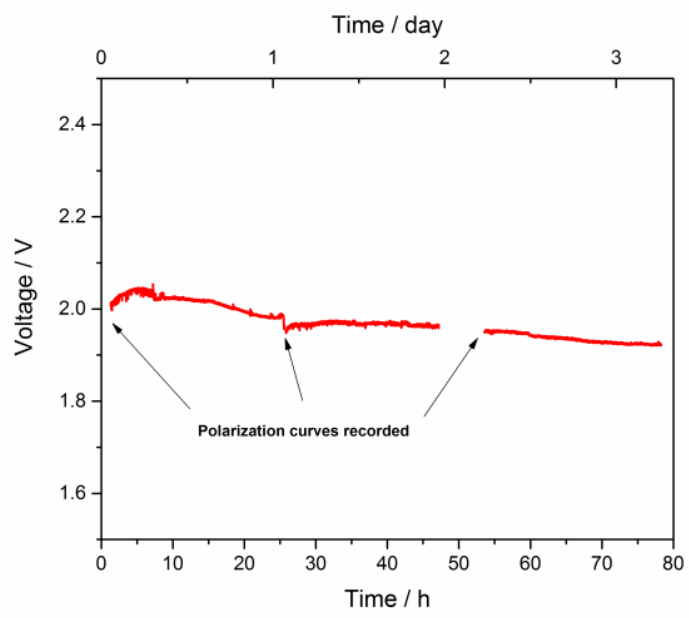

b)

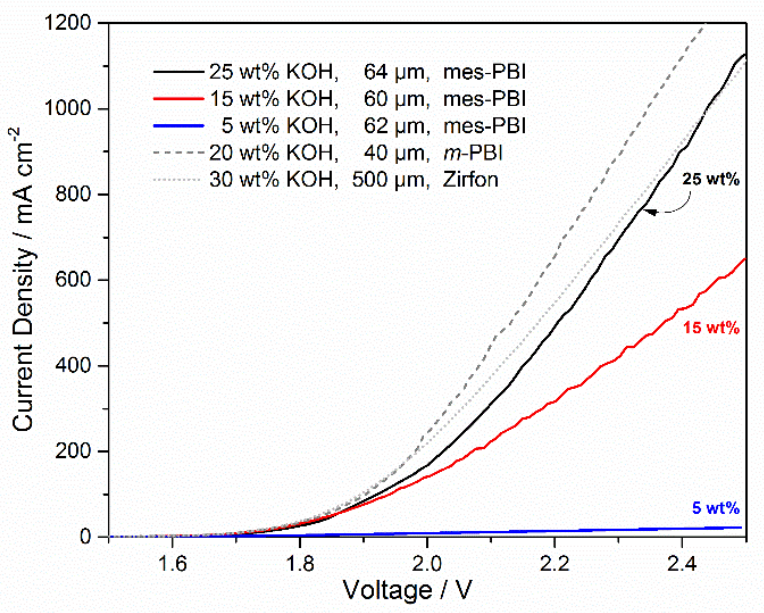

d)

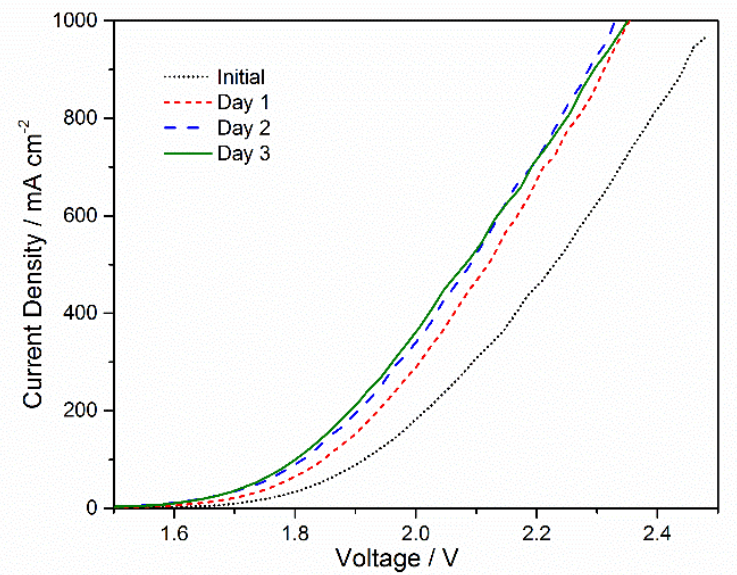

Figure 4 (a) Ion conductivity isotherms of aqueous $\mathrm{KOH}$ (open symbols) and of mes-PBI equilibrated in the corresponding $\mathrm{KOH}$ solutions (solid symbols); (b) Electrolysis polarization characteristics of mes-PBI at $80{ }^{\circ} \mathrm{C}$ at different $\mathrm{KOH}$ concentrations compared with $40 \mu \mathrm{m} \mathrm{m}$ $\mathrm{PBI}$ in $20 \mathrm{wt} \% \mathrm{KOH}$ and $500 \mu \mathrm{m}$ Zirfon in $30 \mathrm{wt} \% \mathrm{KOH}$; (c, d) Chronopotentiometric behavior at $200 \mathrm{~mA} \mathrm{~cm}^{-2}$ and evolution in polarization curves for a cell equipped with a mes-PBI 
membrane operating at $80{ }^{\circ} \mathrm{C}$ in $25 \mathrm{wt} \% \mathrm{KOH}$. Plain nickel foam without additional catalyst was used as electrodes in a zero-gap configuration.

Electrolysis polarization characteristics of cells equipped with mes-PBI membranes at $80{ }^{\circ} \mathrm{C}$ are presented in Figure 4b. Polarization curves for cells equipped with $m$-PBI and Zirfon are shown for comparison. In $5 \mathrm{wt} \% \mathrm{KOH}$ a modest current density of $22 \mathrm{~mA} \mathrm{~cm}^{-2}$ was reached at $2.5 \mathrm{~V}$ for the cell based on mes-PBI, due to the low conductivity of the membrane under those conditions. The cell performance in $5 \mathrm{wt} \% \mathrm{KOH}$ was significantly lower than what can be achieved using Zirfon at low $\mathrm{KOH}$ concentrations (Figure S2). In $15 \mathrm{wt} \% \mathrm{KOH}$, the ion conductivity of mes-PBI at $80{ }^{\circ} \mathrm{C}$ is close to $60 \mathrm{mS} \mathrm{cm}{ }^{-1}$, and a significant current could thus be obtained. At $2.5 \mathrm{~V}$ the cell was operated at about $650 \mathrm{~mA} \mathrm{~cm}{ }^{-2}$. In $25 \mathrm{wt} \% \mathrm{KOH}$, which represents near-optimal condition based on conductivity data, the cell reached more than $1100 \mathrm{~mA} \mathrm{~cm}{ }^{-2}$ at $2.5 \mathrm{~V}$, and showed improved ohmic behavior over the cell equipped with Zirfon in $30 \mathrm{wt} \% \mathrm{KOH}$. The polarization behavior at lower temperatures are available in Figure S3-5. When considering the relative behavior of polarization characteristics at different concentrations against the measured conductivity data, it appears that there is a discrepancy for the measured low concentration conductivity. The relative difference in conductivity between 5 and $15 \mathrm{wt} \% \mathrm{KOH}$ is about a factor of 2 , but the difference in slope in the ohmic region is much larger. In the range 2.2-2.5 $\mathrm{V}$ the difference in slope is about a factor of 40.

To further demonstrate the technical feasibility of the system, a cell was operated at 200 $\mathrm{mA} \mathrm{cm} \mathrm{cm}^{-2}$ for 3 days. The chronopotentiometric behavior is presented in Figure $4 \mathrm{c}$, and the evolution in polarization characteristics is shown in Figure 4d. During the three days of operation, the feed electrolyte was slightly colored by metallic corrosion products from exposed steel 
components. A clear electrode activation was observed over the course of the first day, likely due to anode activation by iron. ${ }^{28}$ The apparent severe metal-ion contamination of the liquid electrolyte clearly demonstrates an exceptional robustness of the system, but the long-term effects of metal ion contamination on the stability of the polymer remains to be evaluated. The electrolyte was levelled after first and second day, and the gap with missing data seen in Figure $4 \mathrm{c}$ around 50 hours is a result of a technical data logging issue.

\subsection{Chemical stability of mes-PBI}

To assess the chemical stability of mes-PBI in aqueous $\mathrm{KOH}$, the membranes were kept in aqueous $\mathrm{KOH}$ with concentrations ranging from $0-50 \mathrm{wt} \%$ at $88^{\circ} \mathrm{C}$ for 207 days. It should be remembered that the conductivity of mes-PBI peaks at concentrations well-below $50 \mathrm{wt} \% \mathrm{KOH}$ at up to $80{ }^{\circ} \mathrm{C}$. The test in $50 \mathrm{wt} \% \mathrm{KOH}$ (which is close to a saturated solution) is carried out as an accelerated test to obtain information about fundamental degradation routes. Sampling was carried out after 2, $14,28,59,99,149$ and 207 days and the mass relative to the initial mass was recorded after extensive washing with water, as shown in Figure 5a. As also observed for $m$-PBI membranes in a similar test, ${ }^{18}$ the data from the initial samplings were scattered which may be due to partial oxidation of the polymer or due to wash-out of remaining impurities after the initial washing procedure. Partial oxidation of the polymer during the long-term experiment will also increase the hydrophilicity of the material so that water is bound more strongly, which in turn would affect the residual water content after drying. In contrast to the $m$-PBI membrane, which spontaneously disintegrated after about 100 days in $50 \mathrm{wt} \% \mathrm{KOH}$ at $88^{\circ} \mathrm{C}$, the mes-PBI remained visually intact after 207 days (see inset photograph in Figure 5a). This sample showed significantly higher weight loss relative to the samples treated in $\mathrm{KOH}$ of lower concentrations, indicating that soluble low 
molecular weight degradation products were formed. It should, however, be remarked that the measurements were carried out on a single series of samples due to limited availability of mesPBI. We are thus lacking a sufficient amount of data to discuss statistical variations, and the results should thus be understood in a more qualitative rather than quantitative way.

The FTIR spectra of mes-PBI after treatment in $0-10 \mathrm{wt} \% \mathrm{KOH}$ at $88^{\circ} \mathrm{C}$ for 207 days were practically identical with that of the reference material (Figure 5b), indicating limited structural changes of the polymer. The weak absorption band around $1660 \mathrm{~cm}^{-1}$ after treatment in $25-50 \mathrm{wt} \%$ $\mathrm{KOH}$ likely originates from stretching vibrations of carbonyl groups formed as degradation products from hydrolysis of the polymer backbone. Such a degradation mechanism would produce an equal amount of free diamine groups with an absorption band at around $1400-1500 \mathrm{~cm}^{-1},^{15 a}$ overlapping with the strong characteristic band assigned to in-plane ring vibration of the benzimidazole groups. ${ }^{29}$ Such diamines are, however, known to be highly unstable under oxidative conditions ${ }^{30}$ and are likely decomposed as they are formed. Although the shape of the peaks in the aromatic region of the ${ }^{1} \mathrm{H}$ NMR spectra (Figure 5c) of mes-PBI slightly changed after treatment in $0-50 \mathrm{wt} \% \mathrm{KOH}$ at $88^{\circ} \mathrm{C}$ for 207 , the peak positions were preserved.

The thermogravimetric curves of mes-PBI after 207 days in 0, 5, 10, 25 and $50 \mathrm{wt} \%$ aqueous $\mathrm{KOH}$ at $88{ }^{\circ} \mathrm{C}$ are shown in Figure $5 \mathrm{~d}$. Like $m$-PBI, ${ }^{18}$ the thermo-oxidative degradation of mes-PBI occurred in 2 steps with onset temperatures at about 509 and 629 for the pristine reference materials (Table 2). No significant changes of the thermo-oxidative stability were observed for the mes-PBI membranes after treatment in $0-10 \mathrm{wt} \% \mathrm{KOH}$ at $88^{\circ} \mathrm{C}$ for 207 days. For the membranes treated in $25 \mathrm{wt} \% \mathrm{KOH}$ the onset temperatures were lowered to 452 and $586{ }^{\circ} \mathrm{C}$. After treatment in $50 \mathrm{wt} \% \mathrm{KOH}$ at $88^{\circ} \mathrm{C}$ for 207 days the onset temperatures were further lowered, showing two distinct onsets at 356 and $543{ }^{\circ} \mathrm{C}$ at about 88 and $74 \%$ remaining mass, respectively. 

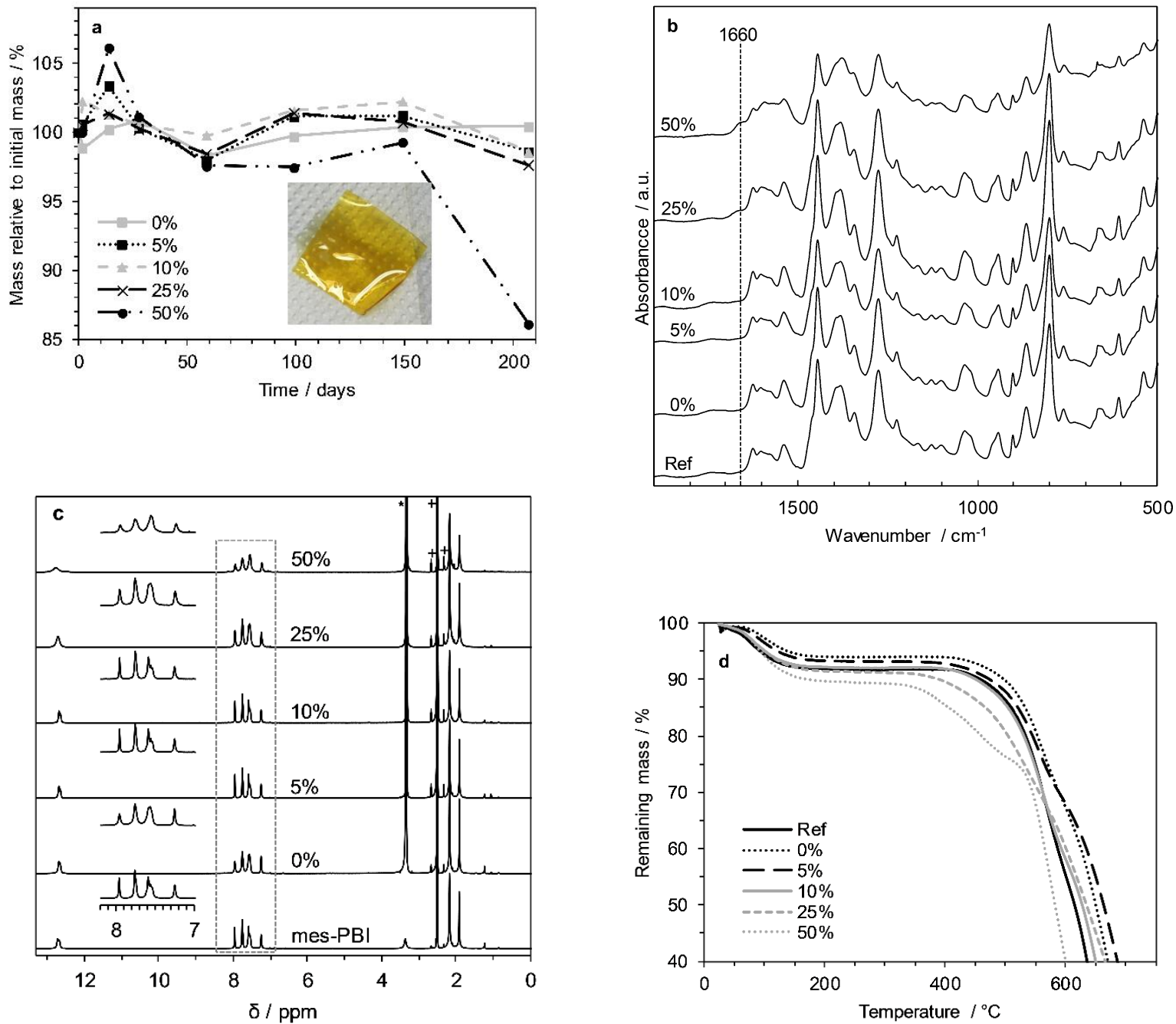

Figure 5 Mass relative to initial mass for mes-PBI after aging in 0, 5, 10, 25 and $50 \mathrm{wt} \% \mathrm{KOH}$ at $88^{\circ} \mathrm{C}$ for up to 207 days, where the inset shows a photograph of the mes-PBI membrane after aging in $50 \mathrm{wt} \% \mathrm{KOH}$ at $88{ }^{\circ} \mathrm{C}$ for 207 days (a). FTIR spectra (b), ${ }^{1} \mathrm{H}$ NMR spectra (c) and TGA data (d) of washed and dried mes-PBI after aging in 0, 5, 10, 25 and $50 \mathrm{wt} \%$ aqueous $\mathrm{KOH}$ at 88 ${ }^{\circ} \mathrm{C}$ for 207 days. The water and solvent residual signals in the ${ }^{1} \mathrm{H}$ NMR spectra are indicated with $*$ and + , respectively. 
Table 2 Onset temperatures of thermo-oxidative decomposition for mes-PBI after aging in 0, 5, 10,25 and $50 \mathrm{wt} \%$ aqueous $\mathrm{KOH}$ at $88{ }^{\circ} \mathrm{C}$ for 207 days. Taken as the intersections of the tangents following the major slopes of the curves.

\begin{tabular}{lcccccc}
\hline & Ref & $0 \%$ & $5 \%$ & $10 \%$ & $25 \%$ & $50 \%$ \\
\hline Onset $1 /{ }^{\circ} \mathrm{C}$ & 509 & 497 & 498 & 502 & 452 & 356 \\
Onset $2 /{ }^{\circ} \mathrm{C}$ & 629 & 643 & 647 & 632 & 586 & 543 \\
\hline
\end{tabular}

The SEC traces of mes-PBI after aging at $88{ }^{\circ} \mathrm{C}$ in $0-50 \mathrm{wt} \% \mathrm{KOH}$ for 207 days are shown in Figure 6a. The shape and position of the peak in the SEC of mes-PBI that had been kept in $\mathrm{KOH}$ with concentrations up to $10 \mathrm{wt} \%$ were nearly identical to that of the reference material, indicating minor changes of the molecular weight. At higher $\mathrm{KOH}$ concentrations, the retention time increased accompanied by peak broadening, clearly indicating reduced molecular weight and enlarged molecular weight distribution. For comparison, m-PBI showed a significant peak broadening and shift to higher retention times after treatment in $10 \mathrm{wt} \% \mathrm{KOH}$ at $88{ }^{\circ} \mathrm{C}$ for 200 days, ${ }^{18}$ which indicate that mes-PBI shows better stability than $m$-PBI in the lower $\mathrm{KOH}$ concentration range.

In $50 \mathrm{wt} \%$ aqueous $\mathrm{KOH}$ the peak retention time increased from 12.74 min for pristine mes-PBI to 13.09, 13.60, 13.74, $14.6314 .90 \mathrm{~min}$ after 14, 28, 99, 149 and 207 days, respectively, further illustrating the gradual decrease of the molecular weight (Figure 6b). The broadening of the peaks further indicates increased molecular weight distribution. The corresponding molecular weight data for all samples as calculated from the PMMA calibration are summarized in Table S2. While the chromatograms showed a clear trend, the molecular weight data obtained from the PMMA calibration was more scattered. This was due to small differences at low retention volumes, 
possibly due to polymer agglomeration. The calibration curve was not linear in this range, which implies that minor differences in retention volume can have a large impact on the calculated molecular weight.

For the purpose of comparison, the SEC traces of $m$-PBI before and after aging in $50 \mathrm{wt} \%$ aqueous $\mathrm{KOH}$ for 200 days at $88^{\circ} \mathrm{C}$ are shown in Figure 6c. The corresponding molecular weight data are summarized in Table 3. The initial molecular weight of $m$-PBI was significantly higher than that of mes-PBI, which complicates the direct quantitative comparison of the alkali-resistance of the two polybenzimidazole derivatives. Both polymers were significantly degraded during the aging test and after $200-207$ days in $50 \mathrm{wt} \% \mathrm{KOH}$ at $88^{\circ} \mathrm{C}$, the $M_{w}$ of mes-PBI and $m$-PBI were about $30 \%$ and $26 \%$ relative to their initial $M_{w}$, respectively.
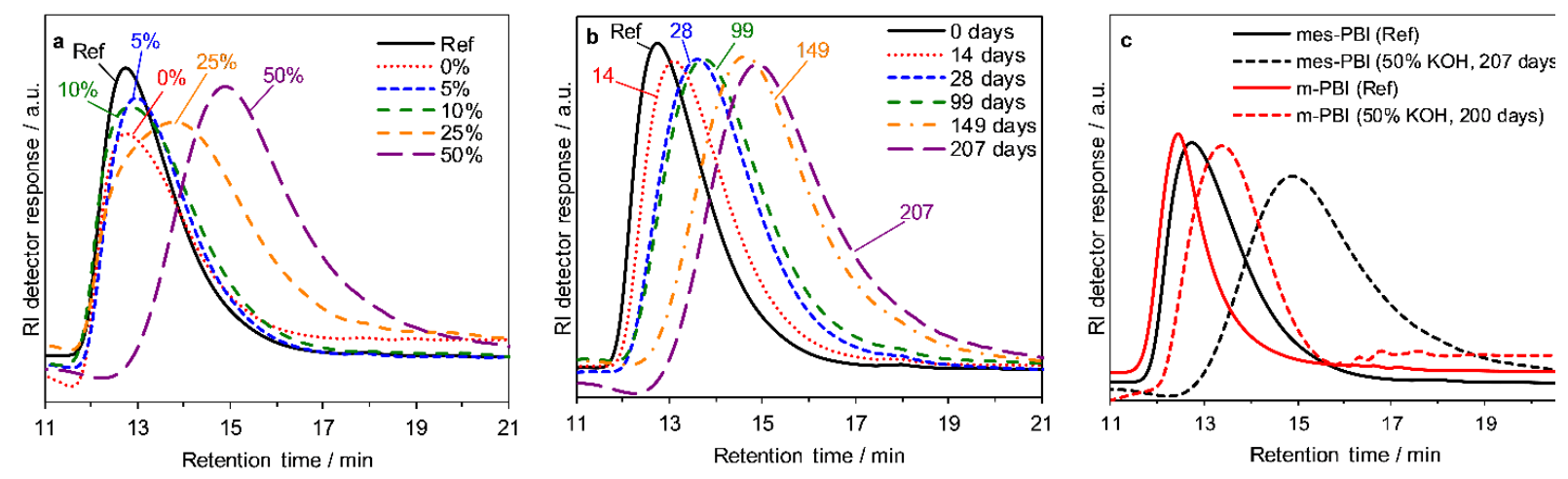

Figure $6 \mathrm{SEC}$ traces of mes-PBI after aging in 0-50 wt $\%$ aqueous $\mathrm{KOH}$ at $88^{\circ} \mathrm{C}$ for 207 days (a) and of mes-PBI after aging in $50 \mathrm{wt} \%$ aqueous $\mathrm{KOH}$ at $88^{\circ} \mathrm{C}$ for different durations (b). Comparison with $m$-PBI before and after aging in $50 \mathrm{wt} \%$ aqueous $\mathrm{KOH}$ at $88^{\circ} \mathrm{C}$ for $200-207$ days (c). Eluent: DMAc + 0.25 wt\% LiCl.

Table 3 Molecular weight data from SEC (relative to PMMA standard) for mes-PBI and $m$-PBI after treatment in 0 and $50 \mathrm{wt} \%$ aqueous $\mathrm{KOH}$ at $88^{\circ} \mathrm{C}$ for 207 and 200 days, respectively. 


\begin{tabular}{|c|c|c|c|c|c|c|}
\hline \multirow[b]{2}{*}{ Conditions } & \multicolumn{2}{|c|}{$M_{p} \times 10^{-3} / \mathrm{g} \mathrm{mol}^{-1}$} & \multicolumn{2}{|c|}{$M_{w} \times 10^{-3} / \mathrm{g} \mathrm{mol}^{-1}$} & \multicolumn{2}{|c|}{$M_{w} / M_{n}$} \\
\hline & mes-PBI & $m$-PBI & mes-PBI & $m$-PBI & mes-PBI & $m-$ \\
\hline & & & & & & PBI \\
\hline Ref & 197 & 362 & 191 & 399 & 2.26 & 3.25 \\
\hline $0 \% \mathrm{KOH}, 88^{\circ} \mathrm{C}, 207 / 200$ days & 189 & 315 & 149 & 315 & 3.16 & 4.08 \\
\hline $50 \% \mathrm{KOH}, 88{ }^{\circ} \mathrm{C}, 207 / 200$ & 43 & 98 & 57 & 102 & 3.36 & 2.36 \\
\hline days & & & & & & \\
\hline
\end{tabular}

Comparing $M_{n}$, which represent the arithmetic mean molecular weight, is likely a better measure of relative stability since it contains information about the number of chain scission events. As a further step towards a direct comparison of the alkali resistance of mes-PBI and $m$-PBI, $M_{n}$ after aging in 10 and $50 \mathrm{wt} \%$ aqueous $\mathrm{KOH}$ at $88^{\circ} \mathrm{C}$ for durations up to 207 days was plotted relative to the initial $M_{n}$ in Figure 7. The data for $m$-PBI were taken from our previous work and acquired using a mobile phase with higher $\mathrm{LiCl}$, which may affect the SEC results since it affects the chain conformation of the polymer in solution. ${ }^{31}$ Although the data are slightly scattered, both polymers show similar $M_{n}$ degradation behavior in $50 \mathrm{wt} \%$ aqueous $\mathrm{KOH}$. In $10 \mathrm{wt} \% \mathrm{KOH}$, it appears as general trend that the relative $M_{n}$ of mes-PBI is slightly higher than of $m$-PBI which supports that the chain scission rate is lower. 


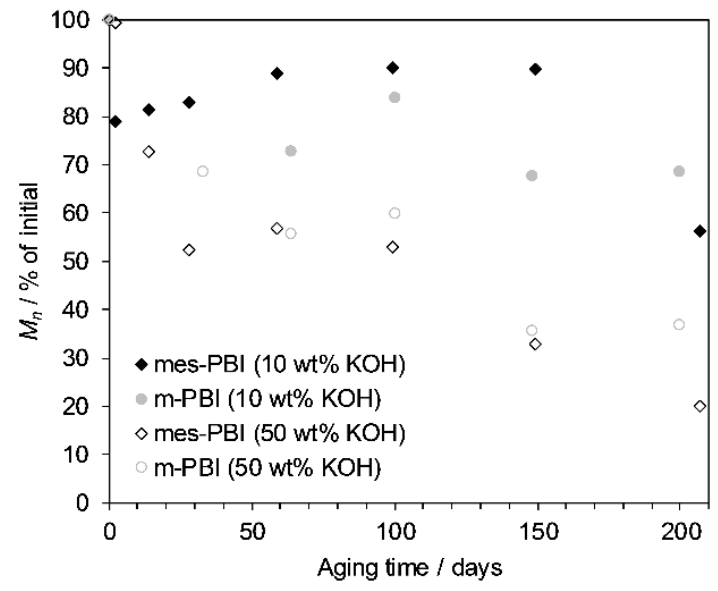

Figure $7 M_{n}$ relative to initial $M_{n}$ for mes-PBI and $m-\mathrm{PBI}^{18}$ at different durations of aging in 10 and $50 \mathrm{wt} \%$ aqueous $\mathrm{KOH}$ at $88^{\circ} \mathrm{C}$. DMAc containing 0.25 and $0.50 \mathrm{wt} \% \mathrm{LiCl}$ was used for mes-PBI and $m$-PBI, respectively.

A degradation pathway of mes-PBI in aqueous $\mathrm{KOH}$ is postulated in Scheme 3. As no significant degradation was observed at concentrations up to $10 \mathrm{wt} \% \mathrm{KOH}$, the degradation is suggested to start from the polybenzimidazolide form of mes-PBI which predominates at $\mathrm{KOH}$ concentrations over $15 \mathrm{wt} \%$. The first step (1) involves nucleophilic addition at the benzimidazolide C2 position. The rate of this step is likely strongly suppressed due to the formal negative charge at the benzimidazole ring. This is followed by ring opening as a result of decomposition of the addition product to form an amide linkage (2), in analogy with the hygrothermal degradation of $m$-PBI. ${ }^{32}$ The amide is subsequently hydrolyzed (3) resulting in complete chain scission. 

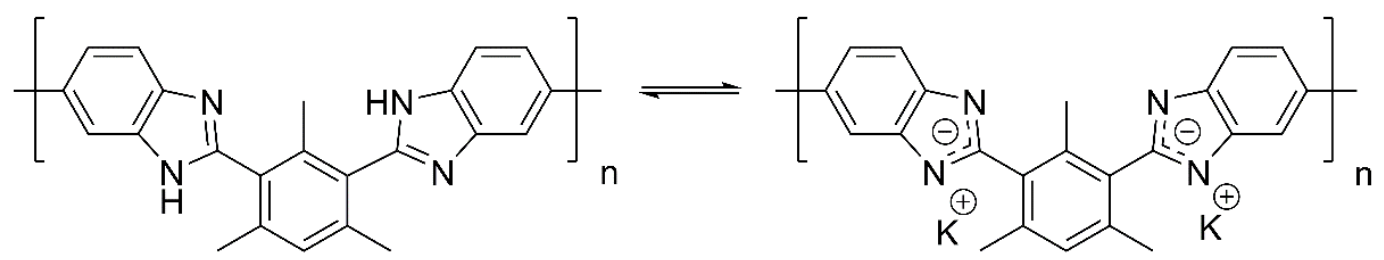

$\downarrow(1)$
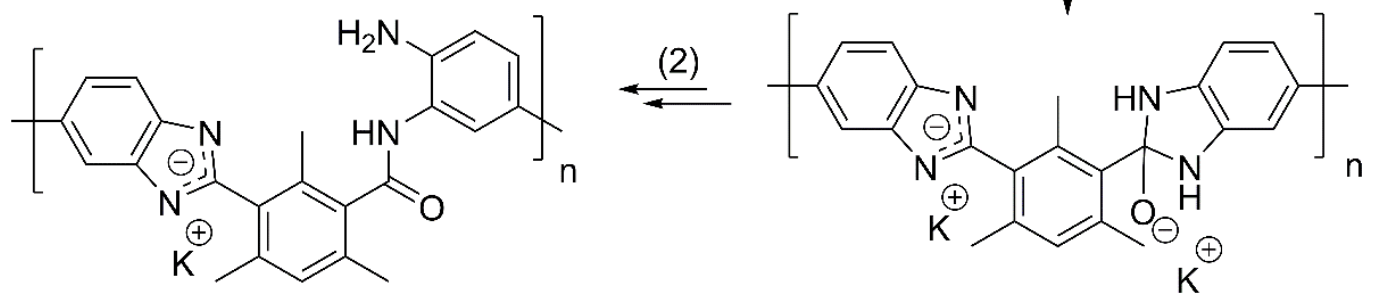

(3)

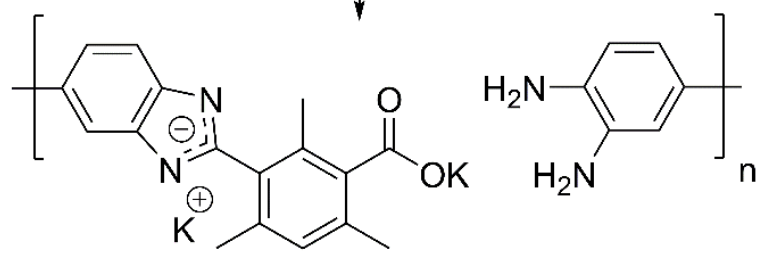

Scheme 3 Postulated degradation pathway of mes-PBI in aqueous $\mathrm{KOH}$.

As previously reported, ${ }^{20}$ steric crowding above and under the benzimidazole plane effectively protects the benzimidazole $\mathrm{C} 2$ position from nucleophilic attack by hydroxide ions. When the $\mathrm{KOH}$ concentration is increased the equilibrium in Scheme 2 is shifted towards the benzimidazolide form of mes-PBI, which predominates at $\mathrm{KOH}$ concentrations higher than about $15 \mathrm{wt} \%$. The ionization of the polymer likely changes the dihedral angle between the benzimidazole group and the mesitylene groups, which in turn changes the effectiveness of the steric protection. This could eventually explain the apparent loss of stabilization in the high $\mathrm{KOH}$ concentration regime, but further studies are needed to clarify this.

After the electrolysis test in $25 \mathrm{wt} \% \mathrm{KOH}$ at $80{ }^{\circ} \mathrm{C}$ for 3 days, the cell was disassembled and the mes-PBI was characterized after extensive washing with water. As can be seen from the 
FTIR and ${ }^{1} \mathrm{H}$ NMR spectra (Figure S7a-b), the mes-PBI membrane showed no signs of enhanced degradation. For comparison, $m$-PBI showed signs of oxidative degradation and polymer chain scission after 2 day of electrolysis operation under similar conditions. ${ }^{16 \mathrm{~b}}$

The results presented herein clearly demonstrate the technological feasibility of mes-PBI as a base material of alkaline ion-solvating membrane. Furthermore, the results from the chemical stability study in aqueous $\mathrm{KOH}$ indicate that mes-PBI show improved alkali-resistance compared to $m$-PBI at $\mathrm{KOH}$ concentrations up to at least $10 \mathrm{wt} \%$. Higher degradation rates were recorded in the higher $\mathrm{KOH}$ concentration range, pointing at the importance of further structure optimization towards the development of new alkali-resistant polybenzimidazole derivatives for alkaline ionsolvating membranes.

\section{Experimental}

\subsection{Materials}

All reagents and solvents were reagent grade, purchased from Sigma Aldrich, and used without further purification, unless otherwise mentioned. Potassium carbonate and dimethylsulfoxide (DMSO) were purchased from ACP Chemicals Inc.. $N, N$-dimethylformamide (DMF), activated charcoal (G-60), and concentrated hydrochloric acid ( 37\% aq.) were purchased from Anachemia. 2,4,6-trimethylisophthalic acid was synthesized according to literature. ${ }^{20 a} 3,3^{\prime}$-diaminobenzidine (98\%) was purchased from Kindchem (Nanjing) Co., Ltd and purified according to literature. ${ }^{33}$ Aqueous solutions of $\mathrm{KOH}$ with concentrations of 5, 10, 15, 20, 25, 35 and $50 \mathrm{wt} \%$ were prepared by dissolving $\mathrm{KOH}$ pellets (Sigma Aldrich, assay $\geq 85 \% \mathrm{KOH}, \leq 1 \% \mathrm{~K}_{2} \mathrm{CO}_{3}$ ) in demineralized water. Density measurements were carried out to determine the concentrations by comparison with data in the literature. ${ }^{34}$ The conductivity cell was calibrated using aqueous $\mathrm{KCl}$ conductance 
standards (Sigma Aldrich, 1.0 and $0.1 \mathrm{~mol} \mathrm{~L}^{-1}$ ). The nickel foam (thickness $1100 \mu \mathrm{m}$ ) was purchased from American Elements. Zirfon ${ }^{\mathrm{TM}}$ Pearl 500 UTP was supplied by Agfa.

\subsection{Polymer synthesis and membrane preparation}

The mes-PBI was synthesized using the following modified literature procedure. ${ }^{20 \mathrm{a}}$ In a 3 -neck round-bottom flask, with argon inlet, mechanical stirring rod, and stopper attached, was added 2,4,6-trimethylisophthalic acid $(4.8590 \mathrm{~g}, \quad 23.3 \mathrm{mmol}), \quad 3,3^{\prime}$-diaminobenzidine $\quad$ (5.0015 g, $23.3 \mathrm{mmol}$ ), and poly(phosphoric acid) (PPA, $156 \mathrm{~g}$ ). The atmosphere in the flask was evacuated and re-filled with argon 5 times. During the following experimental steps, the container was then continuously evacuated using a vacuum pump (Welch DuoSeal 1400). The mixture was then heated to $70^{\circ} \mathrm{C}$ and the mechanical stirring was started. After $30 \mathrm{~min}$, the temperature was increased to $110^{\circ} \mathrm{C}$ for an additional $30 \mathrm{~min}$. The temperature was then slowly ramped up to $150{ }^{\circ} \mathrm{C}$ over $4.5 \mathrm{~h}$. The pressure was then returned to atmospheric pressure by refilling with argon. The dark brown viscous solution was poured into water $(3 \mathrm{~L})$, where it formed white fiber. The solid was washed twice with water and then stirred in water $(3 \mathrm{~L})$ with $\mathrm{K}_{2} \mathrm{CO}_{3}$ (solution $\mathrm{pH} \approx 10$ ) for at least $48 \mathrm{~h}$. The collected solid was washed twice with water and then dried for $2 \mathrm{~h}$ in air at $105^{\circ} \mathrm{C}$. The fibers were ground to a fine powder (in liquid $\mathrm{N}_{2}$ ) and then stirred in water $(2 \mathrm{~L})$ with $\mathrm{K}_{2} \mathrm{CO}_{3}(7.5 \mathrm{~g})$ for $1 \mathrm{~h}$. The collected solid was washed with water and dried under vacuum at $100{ }^{\circ} \mathrm{C}$ overnight, yielding $7.96 \mathrm{~g}(97.3 \%)$ of brown powder.

To remove small molecule impurities, the solid was further purified by boiling in DMF (200 mL) for $30 \mathrm{~min}$, cooled to room temperature, and decanted. The solid was then boiled in DMSO (200 mL) for $30 \mathrm{~min}$. While hot, the mixture was poured into water $(3 \mathrm{~L})$. The solid was collected, stirred in water overnight, and dried under vacuum at $80{ }^{\circ} \mathrm{C}$. The solid was heated in a 
mixture of DMSO $(135 \mathrm{~mL})$ and aqueous $\mathrm{KOH}\left(4.3 \mathrm{~g} \mathrm{KOH}\right.$ in $\left.13.5 \mathrm{~mL} \mathrm{H}_{2} \mathrm{O}\right)$ at $70{ }^{\circ} \mathrm{C}$ for $20 \mathrm{~h}$. The dark red solution was decanted into a beaker and, while vigorously stirring, acidified with concentrated aqueous hydrochloric acid $(15.5 \mathrm{~mL})$. The mixture was poured into water $(3 \mathrm{~L})$, and additional concentrated aqueous hydrochloric acid was added $(5 \mathrm{~mL})$. After stirring for two hours, $\mathrm{K}_{2} \mathrm{CO}_{3}$ was added until $\mathrm{pH} \approx 10$. After 30 min of stirring, the solid was collected, washed with water, stirred for at least $48 \mathrm{~h}$ in $\mathrm{pH} \approx 10$ water ( $3 \mathrm{~L}$ water with $\mathrm{K}_{2} \mathrm{CO}_{3}$ ), collected, washed with water, and dried under vacuum at $80{ }^{\circ} \mathrm{C}$ to yield $6.54 \mathrm{~g}(80.0 \%)$ of purified mes-PBI as fluffy brown solid. The intrinsic viscosity $[\eta]$ was $0.84 \mathrm{dL} \mathrm{g}^{-1}$, as calculated according to the single point method ${ }^{35}$ from viscosity data acquired at $25{ }^{\circ} \mathrm{C}$ using a RheoSense viscometer at a shear rate of $5000 \mathrm{~s}^{-1}$ and a solid content of $0.3 \mathrm{~g} \mathrm{dL}^{-1}$ in DMSO. ${ }^{1} \mathrm{H}$ NMR (500 MHz, DMSO-d 6 , ppm) $\delta: 12.71$ (s, 2H), 8.08-7.46 (m, 6H), $7.24(\mathrm{~s}, 1 \mathrm{H}), 2.17(\mathrm{~s}, 6 \mathrm{H}), 1.92(\mathrm{~s}, 3 \mathrm{H})$.

The membranes were cast in a leveled glass dish (filtered $2.3 \mathrm{wt} \%$ mes-PBI in DMSO solution) at $86^{\circ} \mathrm{C}$ for at least $18 \mathrm{~h}$. The membrane was peeled off from the glass, submerged in deionized water for at least $24 \mathrm{~h}$, and air-dried to produce membranes with a thickness of approximately $60 \mu \mathrm{m}$. The same batch of polymer was used for the physicochemical characterization and stability study, while a second batch was prepared for the water electrolysis testing.

\subsection{Membrane characterization}

After equilibrating the membranes in aqueous $\mathrm{KOH}$ with concentrations of $0,5,10,15,25,35$ and $50 \mathrm{wt} \%$ overnight at $88^{\circ} \mathrm{C}$, the compositions were determined gravimetrically by calculating the weight fractions of mes-PBI $\left(X_{m e s-P B I}\right)$, water $\left(X_{\text {water }}\right)$, and $\mathrm{KOH}$ equivalents $\left(X_{K O H}\right)$ as shown in Equation 2, 3 and 4, respectively. Here, $m$ is the weight of the sampled membrane after careful 
blotting with tissue paper, $m_{d r y}$ is the weight of the sampled membrane after drying at $110{ }^{\circ} \mathrm{C}$ for $4 \mathrm{~h}$ and $m_{\text {dedoped }}$ is the weight of the sampled membrane after extensive washing in demineralized water until neutral $\mathrm{pH}$ followed by drying at $110^{\circ} \mathrm{C}$ for $4 \mathrm{~h}$.

$X_{\text {mes-PBI }}=m_{\text {dedoped }} / m$

$X_{\text {water }}=\left(m-m_{d r y}\right) / m$

$X_{K O H}=\left(m_{d r y}-m_{\text {dedoped }}\right) / m$

The changes in surface area and thickness of the membranes were recorded to determine the swelling characteristics on the dry membrane basis.

The chemical stability of the mes-PBI membranes was assessed by cutting the membranes in 35 square shaped pieces with an area of about $5.5 \mathrm{~cm}^{2}$ each. Before the dry weight and dimensions of the mes-PBI membrane samples were recorded, they were individually marked and dried at $110^{\circ} \mathrm{C}$ for $4 \mathrm{~h}$. The mes-PBI membrane samples were subsequently placed in sealed bottles made of polytetrafluoroethylene (PTFE, 5 bottles with 7 samples in each bottle). The bottles were filled with aqueous $\mathrm{KOH}$ (approximately $0.4 \mathrm{~L}$ ) with concentrations of 0, 5, 10, 25 and $50 \mathrm{wt} \%$ and kept in an oven at $88^{\circ} \mathrm{C}$. Sampling was carried out after 2, 14, 28, 59, 99, 149 and 207 days. The weight relative to the initial mes-PBI weight for the sampled membranes is expressed as the weight of the washed and dried sampled membrane relative to its initial dry weight.

The Fourier transform infrared (FTIR) spectra were recorded on a Perkin Elmer Spectrum Two in attenuated total reflectance (ATR) mode. The ${ }^{1} \mathrm{H}$ nuclear magnetic resonance ( ${ }^{1} \mathrm{H}$ NMR) spectra were recorded on a Bruker Ascend operating at $400 \mathrm{MHz}$. Deuterated dimethylsulfoxide (DMSO- $d_{6}$ ) was used as solvent and the solvent residual signal at $2.50 \mathrm{ppm}$ was used as reference. 
X-ray diffraction (XRD) was carried out using a Rigaku MiniFlex 600 equipped with a $\mathrm{Cu} \mathrm{K}_{\alpha} \mathrm{X}$ ray source $(\lambda=1.5418 \AA)$ in the range $5-50^{\circ} 2 \theta$ at a scan speed of $5^{\circ} 2 \theta$ per minute and a stepsize of $0.02^{\circ} 2 \theta$. For the FTIR and XRD measurement on mes-PBI equilibrated in aqueous $\mathrm{KOH}$, the samples were prepared and kept in the corresponding aqueous $\mathrm{KOH}$ solutions and the spectra/diffractograms were recorded immediately after the samples were taken out and carefully blotted with tissue paper. The total exposure time to the ambient air during was about 3-5 and 1012 minutes for the FTIR and XRD measurements, respectively. Thermogravimetric data were acquired under air at a linear heating rate of $10{ }^{\circ} \mathrm{C} \min ^{-1}$, using a Netsch STA 409 PC. Size exclusion chromatography (SEC) was carried out on a Shimadzu HPLC Instrument, equipped with 2 PolarSil columns (100 and $300 \AA$ A) from Polymer Standards Service (PSS) and a Shimadzu refractive index detector. The system was controlled via the LabSolutions GPC software, which was also used for the data processing and calculations. The mobile phase was composed of DMAc containing $0.25 \mathrm{wt} \% \mathrm{LiCl}$. The temperature of the columns was kept at $60{ }^{\circ} \mathrm{C}$ and the flow rate was $1 \mathrm{~mL} \mathrm{~min}{ }^{-1}$. The peak average molecular weight $M_{p}$, number average molecular weight $M_{n}$, weight average molecular weight $M_{w}$ and the polydispersity index PDI $\left(M_{w} / M_{n}\right)$ were calculated based on a calibration using narrow molecular weight poly(methylmethacrylate) (PMMA) standards from PSS in the molecular weight range of $800-1,600,000 \mathrm{~g} \mathrm{~mol}^{-1}$. Scanning electron microscopy (SEM) was carried out on a Carl Zeiss EVO MA10 and the cross-section was prepared by ion-milling using a Hitachi E-3500.

The ion conductivity of the aqueous $\mathrm{KOH}$ solutions and of mes-PBI in the corresponding solutions was measured by electrochemical impedance spectroscopy using a VersaStat 3 from Princeton Applied Research at $10 \mathrm{mV}$ amplitude scanning the frequency range $1 \mathrm{MHz}$ to $10 \mathrm{~Hz}$, as described in more detail elsewhere. ${ }^{16 b}$ 
The water electrolysis tests were performed in a circular lab cell with an active area of 11.6 $\mathrm{cm}^{-2}$. Electrolyte of 5, 15 and $25 \mathrm{wt} \%$ aqueous $\mathrm{KOH}$ was actively circulated through both flow field chambers at $120 \mathrm{~mL} \mathrm{~min}^{-1}$. The membranes were equilibrated in the corresponding electrolyte for at least 3 days prior to cell assembly. Membrane thicknesses were in all cases $60-65 \mu \mathrm{m} \pm 14$ $\mu \mathrm{m}$ after equilibration in aqueous $\mathrm{KOH}$. The electrodes were prepared from nickel foam pressed to a thickness of $210 \mu \mathrm{m}$ and assembled together with mes-PBI membrane and PTFE gaskets, by carefully aligning the components. The cells were conditioned at $20 \mathrm{~mA} \mathrm{~cm}^{-2}(5 \mathrm{wt} \% \mathrm{KOH})$ or 50 $\mathrm{mA} \mathrm{cm}{ }^{-2}$ (15 and $\left.25 \mathrm{wt} \% \mathrm{KOH}\right)$ for 15 minutes, after which polarization curves were recorded by potentiodynamic scans from 1.3 to $2.5 \mathrm{~V}$ at $2 \mathrm{mV} \mathrm{s}^{-1}$. First at room temperature, then at 40, 60 and $80{ }^{\circ} \mathrm{C}$, with 5 minutes in between for temperature stabilization. The temperature was controlled by heating elements in the end plates. A single cell was operated for 3 days in $25 \mathrm{wt} \% \mathrm{KOH}$. Following an initial characterization as described above, the current density was kept at $200 \mathrm{~mA}$ $\mathrm{cm}^{-2}$ at $80{ }^{\circ} \mathrm{C}$ for 3 periods of about 1 day. Between the segments, the electrolyte was levelled and polarization curves were recorded. Cell current-voltage control was managed by an Elektro Automatik EA-PS 3016-20 B unit through a LabVIEW interface. 5-10 data point averaging was applied to smooth selected polarization and durability data to increase readability/clarity.

\section{Conclusions}

Ternary electrolyte systems are obtained by equilibrating membranes of poly(2,2'-(m-mesitylene)5,5'-bibenzimidazole) (mes-PBI) in aqueous $\mathrm{KOH}$ to give apparent one-phase systems, where the composition strongly depends on the concentration of the bulk solution. In $25 \mathrm{wt} \% \mathrm{KOH}$ the electrolyte uptake corresponds to about $10.2 \mathrm{H}_{2} \mathrm{O}$ and $1.2 \mathrm{KOH}$ equivalents per mes-PBI repeat unit, which supports ion conductivity up to $100 \mathrm{mS} \mathrm{cm}^{-1}$ at $80{ }^{\circ} \mathrm{C}$. The polarization characteristics 
and performance stability of a noble-metal-free zero-gap alkaline water electrolyzer constructed around this electrolyte system demonstrate the technological feasibility of the approach. In contrast to $m$-PBI the membranes based on mes-PBI show no apparent degradation during 207 days at 88 ${ }^{\circ} \mathrm{C}$ in aqueous $\mathrm{KOH}$ with concentrations up to $10 \mathrm{wt} \%$. Gradual degradation occurred in the higher concentration regime, likely due to reduced steric protection of the benzimidazole $\mathrm{C} 2$ position of the potassium polybenzimidazolide form of mes-PBI. The results show that further structure optimization is needed towards improved steric protection of the base-polymer in the polybenzimidazolide form, as the stability of the membrane is key towards the development of a cost-efficient and durable advanced alkaline water electrolyzer.

\section{Acknowledgments}

This work was financially supported by DTU Energy and the Natural Sciences and Engineering Council of Canada (NSERC).

\section{References}

1 A. Ursúa, L. M. Gandía and P. Sanchis, Proc. IEEE, 2012, 100, 410.

2 M. Carmo, D. L. Fritz, J. Mergel and D. Stolten, Int. J. Hydrogen Energy, 2013, 38, 4901.

3 X. H. Li, F. C. Walsh and D. Pletcher, Phys. Chem. Chem. Phys., 2011, 13, 1162.

4 D. Pletcher, X. Li and S. Wang, Int. J. Hydrogen Energy, 2012, 37, 7429.

5 D. Pletcher and X. Li, Int. J. Hydrogen Energy, 2011, 36, 15089.

6 M. Schalenbach, G. Tjarks, M. Carmo, W. Lueke, M. Mueller and D. Stolten, J. Electrochem. Soc., 2016, 163, F3197. 
a) Y.-C. Cao, X. Wu and K. Scott, Int. J. Hydrogen Energy, 2012, 37, 9524; b) Y. J. Leng, G. Chen, A. J. Mendoza, T. B. Tighe, M. A. Hickner and C. Y. Wang, J. Am. Chem. Soc., 2012, 134, 9054; c) L. Xiao, S. Zhang, J. Pan, C. Yang, M. He, L. Zhuang and J. Lu, Energy Environ. Sci., 2012, 5, 7869; d) S. H. Ahn, B. S. Lee, I. Choi, S. J. Yoo, H. J. Kim, E. Cho, D. Henkensmeier, S. W. Nam, S. K. Kim and J. H. Jang, Appl. Catal. B, 2014, 154, 197; e) J. Hnát, M. Paidar, J. Schauer and K. Bouzek, Int. J. Hydrogen Energy, 2014, 39, 4779; f) A. G. Wright, J. Fan, B. Britton, T. Weissbach, H.-F. Lee, E. A. Kitching, T. J. Peckham and S. Holdcroft, Energy Environ. Sci., 2016, 9, 2130.

8 a) M. A. Hickner, A. M. Herring and E. Bryan Coughlin, J. Polym. Sci. B Polym. Phys., 2013, 51, 1727; b) J. R. Varcoe, P. Atanassov, D. R. Dekel, A. M. Herring, M. A. Hickner, P. A. Kohl, A. R. Kucernak, W. E. Mustain, K. Nijmeijer, K. Scott, T. W. Xu and L. Zhuang, Energy Environ. Sci., 2014, 7, 3135.

9 G. Merle, M. Wessling and K. Nijmeijer, J. Membr. Sci., 2011, 377, 1.

10 B. Xing and O. Savadogo, Electrochem. Commun., 2000, 2, 697.

11 a) H. Zarrin, G. Jiang, G. Y. Y. Lam, M. Fowler and Z. Chen, Int. J. Hydrogen Energy, 2014, 39, 18405; b) L. Zeng, T. S. Zhao, L. An, G. Zhao and X. H. Yan, Energy Environ. Sci., 2015, 8, 2768.

12 a) A. D. Modestov, M. R. Tarasevich, A. Y. Leykin and V. Y. Filimonov, J. Power Sources, 2009, 188, 502; b) A. Y. Leykin, O. A. Shkrebko and M. R. Tarasevich, J. Membr. Sci., 2009, 328, 86; c) H. Hou, S. Wang, Q. Jiang, W. Jin, L. Jiang and G. Sun, J. Power Sources, 2011, 196, 3244; d) R. N. Couto and J. J. Linares, J. Membr. Sci., 2015, 486, 239.

13 a) K. Matsumoto, T. Fujigaya, H. Yanagi and N. Nakashima, Adv. Funct. Mater., 2011, 21, 1089; b) T. Fujigaya, C. Kim, K. Matsumoto and N. Nakashima, ChemPlusChem, 2014, 
79, 400; c) H. Zarrin, J. Fu, G. Jiang, S. Yoo, J. Lenos, M. Fowler and Z. Chen, ACS Nano, 2015, 9, 2028.

14. C. Xu, J. Yan, Q. Qin, Y. Deng, J. Cheng, Y. Zhang and Y. Wu, RSC Adv., 2016, 6, 19826.

15 a) D. Aili, M. K. Hansen, R. F. Renzaho, Q. Li, E. Christensen, J. O. Jensen and N. J. Bjerrum, J. Membr. Sci., 2013, 447, 424; b) J. O. Jensen, D. Aili, M. K. Hansen, Q. Li, N. J. Bjerrum and E. Christensen, ECS Trans., 2014, 64, 1175.

16 a) L. A. Diaz, J. Hnát, N. Heredia, M. M. Bruno, F. A. Viva, M. Paidar, H. R. Corti, K. Bouzek and G. C. Abuin, J. Power Sources, 2016, 312, 128; b) M. R. Kraglund, D. Aili, K. Jankova, E. Christensen, Q. Li and J. O. Jensen, J. Electrochem. Soc., 2016, 163, F3125.

17 a) L. Zeng, T. S. Zhao, L. An, G. Zhao and X. H. Yan, J. Membr. Sci., 2015, 493, 340; b) D. Aili, K. Jankova, J. Han, N. J. Bjerrum, J. O. Jensen and Q. Li, Polymer, 2016, 84, 304.

18 D. Aili, K. Jankova, Q. Li, N. J. Bjerrum and J. O. Jensen, J. Membr. Sci., 2015, 492, 422.

19 E. C. Chenevey, Ultrafine polybenzimidazole (PBI) fibers, NASA CR-159644 final report, 1979.

20 a) O. D. Thomas, K. Soo, T. J. Peckham, M. P. Kulkarni and S. Holdcroft, J. Am. Chem. Soc., 2012, 134, 10753; b) A. G. Wright and S. Holdcroft, ACS Macro Lett., 2014, 3, 444; c) A. G. Wright, T. Weissbach and S. Holdcroft, Angew. Chem. Int. Ed., 2016, 55, 4818.

21 Q. Li, R. H. He, R. W. Berg, H. A. Hjuler and N. J. Bjerrum, Solid State Ionics, 2004, 168, 177.

22 a) R. R. Chandran, R. S. Yeo and D. T. Chin, Electrochim. Acta, 1985, 30, 1585; b) D. Aili, M. K. Hansen, J. W. Andreasen, J. Zhang, J. O. Jensen, N. J. Bjerrum and Q. Li, J. Membr. Sci., 2015, 493, 589. 
23 a) R. Bouchet and E. Siebert, Solid State Ionics, 1999, 118, 287; b) Z. Chang, H. Pu, D. Wan, L. Liu, J. Yuan and Z. Yang, Polym. Degrad. Stab., 2009, 94, 1206; c) J. H. Liao, Q. F. Li, H. C. Rudbeck, J. O. Jensen, A. Chromik, N. J. Bjerrum, J. Kerres and W. Xing, Fuel Cells, 2011, 11, 745.

24 a) S. C. Kumbharkar and U. K. Kharul, Eur. Polym. J., 2009, 45, 3363; b) S. C. Kumbharkar, M. N. Islam, R. A. Potrekar and U. K. Kharul, Polymer, 2009, 50, 1403.

25 H. Hou, G. Sun, R. He, B. Sun, W. Jin, H. Liu and Q. Xin, Int. J. Hydrogen Energy, 2008, 33, 7172 .

26 R. J. Gilliam, J. W. Graydon, D. W. Kirk and S. J. Thorpe, Int. J. Hydrogen Energy, 2007, 32, 359 .

27 M. G. Marino, J. P. Melchior, A. Wohlfarth and K. D. Kreuer, J. Membr. Sci., 2014, 464, 61.

28 S. Klaus, Y. Cai, M. W. Louie, L. Trotochaud and A. T. Bell, J. Phys. Chem. C, 2015, 119, 7243.

29 P. Musto, F. E. Karasz and W. J. MacKnight, Polymer, 1993, 34, 2934.

30 J. Liao, J. Yang, Q. Li, L. N. Cleemann, J. O. Jensen, N. J. Bjerrum, R. He and W. Xing, J. Power Sources, 2013, 238, 516.

31 C. B. Shogbon, J. L. Brousseau, H. F. Zhang, B. C. Benicewicz and Y. A. Akpalu, Macromolecules, 2006, 39, 9409.

32 P. Liu, M. Mullins, T. Bremner, J. A. Browne and H.-J. Sue, Polymer, 2016, 93, 88.

33 H. Schubert, K. Baessler (Hoechst AG), US Patent 4433168, 1984.

34 Section 5: concentrative properties of aqueous solutions: density, refractive index, freezing point depression, and viscosity, in CRC Handbook of Chemistry and Physics, 93rd Edition 
(Internet Version 2013), (Ed: W. M. Haynes), CRC Press/Taylor and Francis Boca Raton, FL, U.S.A. Internet Version 2013.

35 Y. Yuan, F. Johnson and I. Cabasso, J. Appl. Polym. Sci., 2009, 112, 3436. 